INDEPENDENCE AND MOBILITY IN LATER LIFE

\author{
Tim Schwanen ${ }^{1, *}$ \\ David Banister ${ }^{1}$ \\ Ann Bowling ${ }^{2}$ \\ ${ }^{1}$ Transport Studies Unit \\ School of Geography and the Environment \\ University of Oxford \\ ${ }^{2}$ Faculty of Health and Social Care \\ St George's, University of London and Kingston University, London \\ ${ }^{*}$ Corresponding author \\ e-mail: tim.schwanen@,ouce.ox.ac.uk \\ phone: +44 (0)1865 285503 \\ fax: $+44(0) 1865275885$
}

First submission: 17 June 2011

Revised submission: 4 January 2012

Final submission: 2 April 2012 


\title{
INDEPENDENCE AND MOBILITY IN LATER LIFE
}

\begin{abstract}
This paper explores independence in later life and its relations with mobility, or embodied movements through physical space on the basis of a review of a range of academic literature and in-depth interviews with community-dwelling adults aged 70 and more in the UK. We suggest that independence is a complex and fuzzy notion that is best thought of as a qualitative multiplicity and as an unstable achievement fabricated out of dependencies on bodies, technologies, infrastructures, social networks and other elements. Yet we also find that the study participants understand independent mobility as avoiding lifts provided by next of kin, friends or others for getting around. This is tied to the enactment of particular forms of embodiment and ageist subject positions for older people and implies that older adults are inadvertently complicit in the perpetuation of the connotations of dependency in later life with passivity, burden and undesirability. To counteract these tendencies, we end this paper by elaborating more inclusive and broader conceptualisations of dependence, independence and independent mobility in later life.
\end{abstract}

Keywords: ageing, mobility, independence, embodiment, subjectivity, UK 


\section{1| Introduction}

Independence in later life features prominently in a number of discourses and is a key concern to multiple constituencies. It is considered crucial to quality of life and wellbeing by older people and policy-makers in the UK and elsewhere (Audit Commission, 2004; Gabriel and Bowling, 2004; Ziegler and Schwanen, 2011). Independence is also an important dimension of successful ageing (Rowe and Kahn, 1987), which is perhaps best understood as "the capacity of older people to thrive" (Depp and Juste, 2006, page 5). Further, in addition to participation, care, selffulfilment and dignity, independence is one of the United Nations Principles for Older People, which were adopted by the UN General Assembly in 1991 and have been promoted since (United Nations, 2002). Likewise, the WHO considers maintaining autonomy and independence crucial to active ageing - the continuing participation in social, economic, cultural, spiritual and civic affairs in later life (World Health Organization, 2002).

Perhaps because of its popularity and widespread use, independence in later life is understood in a wide variety of ways. Hence, the meanings of and practices regarding independence in particular contexts need to be scrutinised carefully and critically. Critical analysis is also warranted because the promotion of independence in later life is linked to neoliberal systems of governance in the Anglo-American world (Laliberte Rudman, 2006; Portacolone, 2011). This promotion is an integral part of the neoliberal shifts in and rescaling of responsibilities with regard to health, wellbeing and social care from the state to the level of older people themselves, and to a lesser degree their networks of relatives, friends and others. Geographers and/or those sensitive to older people's engagements with their environment are arguably well positioned to conduct such enquiries, especially if we think of independence - however defined - as emerging from the interface of bodily capacities and the socio-material contexts in which (older) people are situated. However, whilst geographers have made key contributions to the closely affiliated literature about 
ageing in place (Rowles, 1993; Cutchin 2003; see also Andrews et al., 2007), they have written less about independence in later life beyond independent living than colleagues in other disciplines.

Therefore, this article explores independence in later life through a geographical lens. We consider both the meanings that older people from across the UK attribute to independence and how they practice independence in the realm of everyday mobility, or embodied movement through physical space. This is not to suggest that mobility is necessarily the domain of everyday life in which independence features most prominently for the older people in our empirical study or more generally; independent living and being with relatives and friends on one's own terms, for instance, can be just as important. Nor do we wish to suggest that what holds for independence in relation to mobility necessarily extends to other domains of older people's everyday life. Our focus on mobility derives from the fact that independent living and active ageing presuppose a minimum level of capacity to be/become mobile in older adults; mobility is important because it links together practices within the home and relevant sites elsewhere and enables wellbeing in later life. In focusing on the links between independence and mobility in later life, we also seek to forge further links between the work of geographers interested in ageing and old age and that of cultural geographers and sociologists interested in mobilities (Urry, 2007; Adey, 2010; Cresswell, 2011). Older adults have received only scant attention in the burgeoning literature about mobilities (but see Lucas and Burnett, 2010; Ziegler and Schwanen, 2011). This can be considered a missed opportunity given that mobility as an embodied practice often changes in later life and this mobility offers myriad opportunities for examining the social construction of ageing, identities and subjectivities. 


\section{2| Independence in the academic literature}

\subsection{Self-reliance and other liberal-individualistic understandings}

Independence has long been debated in gerontology, medicine, nursing, sociology, social work, disability studies and other academic disciplines. It is an often invoked yet ill-defined term whose meaning is frequently taken for granted. According to Plath (2008), interpretations of independence in later life in those literatures vary from those that foreground individual capacities to those that understand independence in terms of accessing resources for the satisfaction of individual needs, and to those whereby independence and dependence are considered social constructions ( $c f$. the work by Townsend [1981] and others on structured dependency). Individualistic understandings of independence nonetheless prevail: Independence is here understood as the ability to function unaided and as the absence of dependence or reliance on others for carrying out everyday activities. This conceptualisation pervades the thinking of social care professionals, service providers, health scientists and clinicians (Leece and Peace, 2010; Plath, 2008; Struhkamp et al., 2009) and chimes with medical frameworks centred on reducing limitations of individual capacities (Clapton and Kendall, 2002).

In the gerontological literature the understanding of independence as functioning unaided has been criticized on various grounds. Firstly, Secker and colleagues (2003) argue that this understanding of independence is rooted in Anglo-American culture and its emphasis on the ideal of the autonomous, self-actualising individual. Especially in the UK and USA, self-reliance is highly valued and being dependent on others is a sign of weakness. However, non-Western cultures as well as some social groups within Western societies understand dependence on others in more positive terms (Stephenson et al., 1999). Secondly, it has been argued that understanding independence as not depending on others reflects the dominance of hegemonic masculinity in 
Western societies, according to which men are expected to be self-reliant, autonomous, physically competent, strong and so on (Smith et al., 2007). What this suggests, then, is that understanding independence primarily in terms of functioning unaided is contingent on geography and history.

Thirdly, empirical studies of people's situated understandings of independence have shown independence to be multidimensional and mutable (Rock, 1988; Mack et al., 1997; Ball et al., 2004; Plath, 2008). It is multidimensional because older and disabled people ascribe multiple meanings to the notion. Ball and colleagues (2004), for instance, found that residents of assisted living units in Georgia, USA understood independence as self-reliance, avoiding dependency, retaining functional ability, reciprocity, autonomy, meaningful activity, valued role and continuity of identity. Independence is mutable because people redefine the notion over time as their situation changes: The participants in Ball et al.'s study reduced their expectations regarding independence over time so that these matched their decreased bodily capacities.

The disability movement has also sought to shift understandings of independence beyond people's competence to conduct activities of daily living unaided (Brisenden, 1986; Rock, 1988; Reindal, 1999). For Brisenden (1986) independence is not doing everything oneself but having control over one's life and choosing how that life is led. Independence is therefore (also) related to people's decision-making. Many authors have, therefore, tied independence to autonomy. Secker et al. (2003) propose a two-dimensional model of independence, with one dimension reflecting the degree of reliance on others and the other the subjective assessment of autonomy, desired level of choice and social usefulness. And Clapton and Kendall (2002) and Leece and Peace (2010) follow Collopy (1988) in distinguishing between decisional and executional autonomy. The former indicates the ability and freedom to make decisions without external coercion or restraint and reflects what Brisenden and others foreground; the latter refers to the 
ability and freedom to carry out and implement personal choices and is related to the idea of selfreliance (Leece and Pearce, 2010).

Understanding independence as decisional and executional autonomy is more comprehensive that the notion of independence as self-reliance. It also enables bringing together independence and social connectedness, which is so important to older people's wellbeing (Gabriel and Bowling, 2004; Breheny and Stephens, 2009; Ziegler and Schwanen, 2011). It is thus possible for older adults to be independent in the sense of capable of making and implementing decisions about participation in the local community or about when, where and how to interact with relatives, friends and others. However, all conceptualisations of independence discussed so far rest on a liberal-individualistic and modernist understanding of subjectivity, heavily informed by the works of Immanuel Kant, John Stuart Mill and like-minded thinkers. ${ }^{1}$ As various disability researchers and others have argued (Reindal, 1999; Cardol et al., 2002; Weicht, 2010), liberalindividualistic understandings are problematic as they do not adequately recognise and conceptualise human embodiment and the fundamental enmeshment of individuals in relations with other humans, other forms of life, technical artefacts and other forms of inanimate matter. They inevitably if implicitly privilege independence over dependence and interdependence, positioning the latter as occasional rather than as indispensible to human life (Reindal, 1999).

\subsection{A non-modernist understanding of in/ dependence}

Over the past decades scholars have begun to rethink independence within alternative philosophical frameworks, including feminist philosophy (Fine and Glendinning, 2005),

\footnotetext{
${ }^{1}$ There of course exist differences between these thinkers' writings on independence and autonomy. For Kant (1997[1985]), for instance, autonomy revolved around the ability to govern oneself without domination by others and was closely linked to reflective thought and rationality. In On Liberty Mill (1859) understands autonomy in terms of self determination and expression of one's will and desires. Despite these differences, the general thrust of both thinkers' arguments continues to have a deep impact on contemporary thinking about independence.
} 
existential phenomenology (Reindal, 1999), actor-network theory (ANT) (Struhkamp et al., 2009) and combinations thereof (Struhkamp, 2005; Schillmeier, 2008; López and Domènech, 2009). A perspective that combines ANT with phenomenology sheds a unique light on independence, we suggest, because it shifts attention away from attempts to stabilize its meanings towards the processes through which independence emerges and evolves. Two key insights this perspective offers are that independence is fabricated out of myriad relations or attachments, and that it is a precarious achievement requiring constant work.

As is well-known, a central tenet of ANT is that agency is the outcome of a process of association (Law, 1986; Latour, 1987): actants, including persons, can act if they are linked to other people and a host of heterogeneous material artefacts within a hybrid collectif (Callon and Law, 1995) or assemblage (Anderson and McFarlane, 2011). Like agency, subjectivities - ways of being and doing - are distributed across the heterogeneous entities in assemblages. In recent years these ideas have been extended to dis/ability and in/dependence. Ingunn Moser has shown that dis/abilities emerge from people's relations with other entities, and that the configurations of those relations at particular times and place enact dis/ability in specific ways (Moser and Law, 1999; Moser, 2006). Myriam Winance (2007) argues that for wheelchair users action results from a long process of negotiation or material and emotional adjustment between a person, the wheelchair and other actants. This adjustment is material because the links between person, wheelchair and others are continually remade - for instance, when a new wheelchair is tried out, when footrests are lowered, or when the person changes her position in the chair. This reconfigures the body-in-the-wheelchair and opens up new possibilities of action (whilst foreclosing others). The adjustment is emotional in that devices like the wheelchair or components thereof need to be integrated into the person's lived body - the body one is, through which one participates in and perceives the world, and that emerges from the interactions between the body of bones and flesh and its social and material environment (Merleau-Ponty, 
1962; Butler and Bowlby, 1997) - for the actions of the body-with-wheelchair to become fluid habitual. It is only then that competences become distributed within the assemblage and that a split between object and subject emerges, and that space opens up for a sense of control or for autonomy.

Winance's work (2007) thus suggests that independence and autonomy are products of relations and achievements. Whilst she foregrounds the longer-term processes through which independence is produced, Schillmeier (2008) emphasises how dis/ability and in/dependence are continually made and re-made in the continuous flows of encounters and situations in everyday life. He draws on Heidegger's (1962) distinction between Zuhanden or ready-to-hand and Vorbanden or present-to-hand. The former indicates a situation of usable and accessible space where things are known and work, the latter a situation of detached arrangements of materialities that alienate and obstruct. Through case-studies of people with visual impairments Schillmeier illustrates how readiness-to-hand and presence-to-hand produce in/dependence. One study participant is able to shop independently in a supermarket because she has memorized its arrangement, which has thus become Zuhanden. But she is no longer able to get her groceries, when the supermarket reorganizes its shelves and its arrangement becomes Vorhanden. For Schillmeier, then, "there is no such thing as dependence or independence, ability or disability" (2008, page 228). These are events or outcomes of the "constant movement between the readiness and presence-at-hand of' (ibid.) the always changing social and material arrangements of which people are part.

\subsection{Independence and mobility}

At least two bodies of literature are relevant to understanding the links between independence and movement through physical space in later life. One is the literature on transport and daily 
trip-making by older people, the other the recent work on mobilities in cultural geography and sociology. In the former the understanding of independence as non-dependence on others is widespread. Multiple studies - mostly set in car-dominated societies such as the USA and Australia - equate being able to drive in later life with self-reliance (Coughlin, 2001; Bauer et al., 2003; Adler and Rottunda, 2006; Davey, 2007). Driving cessation hence implies that older people come to depend on others for getting around to a much greater extent. Many older adults find this problematic out of practical inconvenience and because they do not want to become a burden and impose themselves on others (ibid.). Further, older people who do not drive themselves sometimes prefer other modes of travel over being driven around. In focus-groups with adults aged 75 and over in Massachusetts, Coughlin (2001) found that one advantage of public transport over getting rides was that it afforded more self-reliance. And a quantitative study of transport mode use in Greater London showed that older adults preferred not to be driven by others, possibly because they disliked being dependent on friends or family for rides (Schmöcker et al., 2008). However, a study by Risser and colleagues (2010) among some 3,300 older people in eight European countries ranked reliance on other people only as the $16^{\text {th }}$ most important barrier with regard to out-of-home mobility, which was well below such factors as the behaviour and attitudes of other traffic participants, the lack of toilet facilities and overcrowding of public transport vehicles. Hence, dependence as reliance on others is a factor of significance in the context of older adults' everyday trip-making but not necessarily of overriding importance.

Understandings of independence in terms of autonomy can be found in the literature about tripmaking in later life but these are more implicit and less frequent than independence as selfreliance. According to some studies (Adler and Rottunda, 2006; Davey, 2007), older people construct driving cessation as a loss of spontaneity, which indicates that being able to drive not only affords executional but also increases decisional autonomy to older people: more so than other modes of transport, cars allows them to go where they want when they want. To the best 
of our knowledge, non-modernist understandings of independence informed by ANT are absent from the existing literature on ageing and trip-making.

There are at least two ways in which the mobilities literature deepens our understanding of the links between independence and mobility. Firstly, inspired by theorisations of reflexive modernisation (Beck et al., 1994) and liquid modernity (Bauman, 2000), scholars have critically examined the interrelations between movement through physical space and freedom (Kesselring, 2006; Sager, 2006; Sheller, 2008; Freudendal-Pedersen, 2009). Freedom is as slippery a concept as independence but both Sheller (2008) and Freudendal-Pedersen (2009) highlight that decisional and executional autonomy are key aspects of freedom and that more mobility is widely considered a symbol and facilitator of more freedom. Both draw on the concept of motility - the ability or potential to be mobile (Kaufmann, 2002) - in this regard, and Freudendal-Pedersen argues that cars are widely perceived as the only transport mode that gives people the motility and autonomy required to live a late modern life. Importantly, however, both authors also argue that the freedom of some comes at the expense of others'. This is exemplified by the inequalities between haves and have-nots that car access and use creates; the system of automobility subordinates and to a certain degree immobilises those who cannot use a car (see also Urry, 2007). Further, despite connotations of autonomy, car use and motility also create unintended consequences in the forms of social expectations (ibid.; Freudendal-Pedersen, 2009): its users are almost obliged to choose the best rather than the nearest shop, cultural event, workplace, and so on. In short, cars and the system of automobility create freedoms and unfreedoms for car users and non-users.

Secondly, mobility scholars have critically examined the concept of children's independent mobility, which highlights the growing prevalence of parents driving children to places and decrease over time in the latter travelling alone (Hillman et al., 1990). Whilst individuality and 
autonomy in young people are quite different from those in later life, mobility scholars' critiques of children's independent mobility are insightful for various reasons. Mikkelsen and Christensen (2009) argue that the concept suffers from a built-in cultural bias favouring self-reliance - a privileging that seems to extend to later life - and Kullman (2010) suggests that children's independent mobility is 'crafted' (Law, 2004) out of specific relations between bodies, technologies and infrastructures. Children moving dependently are enmeshed in bundles of relations in which parents play a key role, whereas those moving independently are part of relational arrangements in which - at least in Kullman's empirical study - mobile phones, extensively practiced routes, and specific skills feature more prominently. Thus, children's independent mobility is an outcome, much like Winance (2007) and Schillmeier (2008) suggested with regard to the mobility of dis/abled persons.

\section{4 | Examining independence and mobility}

In light of the preceding discussions, this article considers both how older people talk about independence and how they enact it in everyday mobility in the physical world. We concentrate on older adults' talk about independence for three reasons. Analysing older people's narratives enables us to firstly gain further insight into the multidimensional and mutable meanings of independence in later life ( $c$. Ball et al., 2004; Plath, 2008) and secondly to probe independence as a multiplicity. Here the question is whether independence as lived and enacted by older adults is a multiplicity as defined by Annemarie Mol and John Law (Mol, 2002; Law, 2004) or more along the lines of Henri Bergson (1913). For Mol and others, objects as diverse as atherosclerosis, warplanes, water pumps, alcohol liver disease and gardens are enacted in practices in many different ways (De Laet and Mol, 2000; Mol, 2002; Law, 2004; Hinchliffe, 2010). They are neither stable, singular phenomena; nor are they plural or several different objects. There are different 
versions that overlap, are partially connected and include each other but these are also not the same. And independence may also be such a multiple - more than one but less than many.

Henri Bergson (1913) distinguished between two forms of multiplicity. One he called quantitative multiplicity, which denotes a phenomenon consisting of discrete states that are externalised to each other, and his archetypal example is the clock. The other he labelled qualitative multiplicity, which signifies an organic whole in which differences permeate and melt into one another. A melody exemplifies this multiplicity well as it organises tones into an organic whole. A key difference between the ANT and Bergsonian conceptualisations concerns the role of language. For Mol and Law language use is one way of managing and ordering multiplicity, whilst for Bergson it is a key factor in the subordination of qualitative to quantitative multiplicities. This is because on his view words arrest the shifting character and fluidity of qualitative multiplicities, solidifying them in quantitative ones. If independence can be understood best as a qualitative multiplicity, then it cannot be reduced to a linguistic construction. Some of its aspects will then elude research that seeks to enumerate its meanings from older adults' narratives, and further analysis of how independence is practiced in specific settings, including those associated with mobility through physical space, will be warranted.

The third reason for analysing older adults' talk about narrative is that it offers a lens on the production of subjectivities in later life. Following Weicht (2010) and others, we may expect older people in such countries as the UK to discursively dissociate themselves from dependence on others in an interview setting, as dependency is associated with passivity, lack of agency and moral inferiority. They would thereby not only position themselves as virtuous older adults or ageless subjects (Kaufman, 1986) but also make older adults who are dependent on next of kin or others into 'the other' against which one's own life circumstances can be evaluated favourably. 
We focus on mobility - actual and potential embodied movement through physical space because this is an important dimension of independence requiring geographical analysis and is particularly well suited for examining how independence is practiced and brought into being. We will elaborate how in later life independence in mobility is fabricated out of dependencies on bodies, artefacts, infrastructures and social networks ( $c f$. Winance, 2007; Schillmeier, 2008; Kullman, 2010), as well as such social conditions as available income. One of our arguments will be that independent mobility in later life is broader than not depending on next of kin or others for providing rides. It rather pertains to the character of the sociomaterial dependencies in which older people are enmeshed and of older adults' capacities for shaping and sorting those dependencies at least to some extent. Autonomy is implicated but we do not have to sign up to the ideal of the (older) individual as a sovereign, self-directed decision-maker, which underpins many liberal-individualistic understandings of independence (see also Clapton and Kendall, 2002; Hunt and Ells, 2011). It can also be understood as relational and distributed across bodies, objects, infrastructures and social networks. Like the ageing body on the move, independence and autonomy are unstable emergences whose character changes continually.

\section{3| Empirical context}

In the remainder of the paper we illustrate and elaborate the above arguments using interviews about older people's understandings of active ageing in the context of a project within the New Dynamics of Ageing programme in the UK (McFarquhar and Bowling, 2008). In total 42 older people aged 70 and over were interviewed. To obtain a diversity of views on and experiences of the ageing process, participants were selected in England (40) and Scotland (2), and on the basis of sex, age, marital status, tenure, physical functioning, self-rated quality of life and population density of the residential area. Table 1 indicates that there is substantial variation in living 
conditions and experiences among the study participants, although owner-occupiers, physically competent older adults and those with a (very) good quality of life are overrepresented.

The interviews were loosely structured around a topic list, conducted in participants' homes and audio-recorded and transcribed verbatim. Building on initial analysis of the transcripts reported on in McFarquhar and Bowling (2008), Schwanen carried out open and axial coding of the transcripts in a series of iterations. Below we report and reflect on the analysis, using a selection of quotes that are representative of participants' understandings and experiences and/or illustrate certain themes and issues aptly or vividly. Pseudonyms are used to ensure participants' anonymity and confidentiality.

Table 1| Characterization of participants

Number of respondents

\begin{tabular}{llr}
\hline \multirow{2}{*}{ Sex } & Male & $18(43 \%)$ \\
& Female & $24(57 \%)$ \\
Age & $70-79$ years & $22(52 \%)$ \\
& $\geq 80$ years & $20(48 \%)$ \\
Marital status & Married or living with a partner & $17(40 \%)$ \\
& Widowed & $18(43 \%)$ \\
Housing tenure & Single or divorced/separated & $7(17 \%)$ \\
& Owned & $33(82 \%)$ \\
Physical competence & Rented & $9(18 \%)$ \\
& Little or no difficulty walking 400 yards & $28(67 \%)$ \\
Self-rated quality of life & Able to walk 400 yards with aid, unable to do so alone & $14(33 \%)$ \\
& Very good, good & $29(69 \%)$ \\
Population density & Very bad, bad, alright & $13(31 \%)$ \\
& Low density & $22(52 \%)$ \\
\end{tabular}




\section{4| On independence}

The analysis showed very clearly that independence is a fuzzy notion with multiple and shifting meanings. Not depending on others was the most widespread meaning, articulated in $79 \%$ of the interviews in which independence was discussed. Consistent with previous studies in an AngloAmerican contexts, our participants valued self-reliance and unaided functioning (very) positively. This understanding did not, however, feature more prominently among male participants.

Various factors were related to participants' reluctance to be dependent on others but the most important was the wish not to be a burden or nuisance to others, especially one's children:

"I couldn't have better family but I still don't to be dependent and don't want to be a nuisance to anybody"

Vicky, 85 years, widowed, urban location in Hampshire

"I'm one of those sort I don't like to bother them [her daughter and grandson]. They've got their lives you know, I've had mine. It doesn't seem right to, you know. I don't think you should have a child as an insurance for your old age, do you?" Mary, 87 years, widowed, village in Cambridgeshire

Mary's words resemble Vicky's but add a temporal component. She does not want to be a burden because of a-synchronicity in the rhythms of life: her children have their lives, she had hers. Other respondents explained their valuing of self-reliance with reference to their own upbringing:

"I suppose it's just the way you've been brought up, you know, to cope on your own."

Peter, 84 years, widowed, urban location in Essex 
And Valerie, a widow of 72 living in a village in Hampshire, also referred to her upbringing and in particular to the ways in which her mother coped with life as an independent and mentally strong woman. In summary, participants' understanding of independence as self-reliance is temporally complex: it involves multiple time scales; is dependent on practices and events earlier in a person's life-course and on recent experiences; and is sometimes animated by notions of what is appropriate to do and expected in different stages of the life-course.

As expected, the participants' inclination towards self-reliance intersected with the production of subjectivities and identities. Valerie, for instance, discussed how difficult her late husband found it to relegate self-care practices, such as cutting his toenails, to her: "he didn't hate me doing it, he hated me having to do it". Her narrative thus reflects the masculine association of self-reliance with strength, pride and competence (cf. Smith et al., 2007). Further, and in line with Weicht (2010), participants associated dependence on others with being old, a condition from which they wanted to dissociate themselves and that they used to position themselves as virtuous older adults or ageless subjects.

A variety of other understandings and meanings of independence also surfaced in the interviews. The second most frequently occurring was ability to do things (58\% of the interviews in which independence was discussed), such as self-care, doing groceries, walking, taking a bus and so on. This suggests that many participants understand independence as a capability, not unlike Amartya Sen's (1999) understanding of this concept as that which people are actually able to be and do. This understanding differs from not depending on others in that this signals 'freedom to' rather than 'freedom from'. Interestingly, independence as ability to do things was discussed in more interviews than the meaning of self-determination or decisional autonomy $(42 \%)$. While this may reflect that the interviews were framed as a study into active ageing, it may also signal that the distinction between deciding as thinking or separable cognitive act and the 'doing' of its 
subsequent implementation is not so sharp for many of our participants as liberal-individualistic understandings of autonomy (Section 2.1) presuppose. This is not to say that the thinking/doing distinction did not resonate with participants, as suggested by Jerome's "I do what I want when I want to do it" (Jerome, 81 years, married, urban location in Nottinghamshire). It is to argue, after 'practice theory' (Reckwitz, 2002), that independence as autonomy was part and parcel of everyday practices in which thinking and doing - and by implication decisional and executional autonomy - were not sharply demarcated and ordered linearly (with the thinking proceeding the doing, as most academic models of decision-making assume) but closely interwoven.

Another widespread understanding of independence was living alone (32\%). This reflects that among community dwelling participants independence follows not only from being able to undertake activities of daily living but also from ageing in place (in the house where they have lived before) rather than with family or in an assisted-living unit. This is because living alone affords privacy, the ability to withdraw from social life, and decisional autonomy (see also Mowl et al., 2000; Haak et al., 2007; Peace et al., 2011), as well as a link with one's past and hence a sense of continuity of self-identity. Anne, an 87-year old widow from an urban location in Lincolnshire, insists on ageing in place rather than moving in with her daughter, as it provides a sense of continuity and decisional autonomy:

"I want to keep here while I can. I mean it isn't, wouldn't be fair to my daughter. I mean she's very good and we get on, and she takes me out and we can have a laugh over a lot of things but then her way of living isn't mine. And I think it wouldn't do, and she's got a cat and I don't like cats [...] and I thought there wouldn't be room for me. No, I like my own things around me and if I want to invite somebody in I can, I'm free to do that, whereas I mean she would want her own friends in and there again, some of them I like and some of them they're not my type at all" (emphasis added) 
Continuity of self-identity, however, was a meaning of independence that surfaced less frequently in the interviews; the same is true for independent physical functioning and the ability to look after oneself. Both meanings are related to ability to do things but are more specific. Physical functioning refers specifically to motor skills, and ability to look after oneself also suggests a sense of moral responsibility people have to care for themselves, significant others and their property.

Although various understandings of independence could be identified from the interviews, these should not be considered independent or exteriorised from each other. This can be seen from Anne's words above, and also from the interview with Jerome: within a short time-span during the interview he alluded to independence as ability to do things, physical functioning, ability to look after oneself, not depending on others and self-determination. In one sense, then, independence can be understood as a multiplicity in the Mol/Law sense: different understandings overlap and include one another but are not the same or reducible to each other. However, from close analysis of the interview transcripts we also sense an elusiveness to independence that continually escapes language and is in excess of what can be described with words. There seems to be a fluidity that underpins and binds together different expressions and manifestations of independence and that makes independence an organic whole. We therefore propose that Bergson's (1913) qualitative multiplicity is the most useful concept to capture the character of independence in later life. To foreground some of its aspects that will elude linguistic analyses, we now turn to an analysis of how independence is practiced and brought into being in the context of older adults' mobility outside the home.

\section{5 | Independence and mobility}

\section{1| Multiple links}


For most study participants there were close links between independence and embodied movements through physical space outside the home for such everyday activities as grocery shopping, religious activities, clubs and visits to relatives, friends and others. These links were multiple, complex and dependent on context, or the particularities of place and time. One way in which these links became evident was that independence and mobility were shown to be linked reciprocally (see also Ziegler and Schwanen, 2011): not depending on others, ability to do things, self-reliance and living alone triggered more (frequent) mobility, which in turn often sustained independence. Another way in which links manifested themselves was that many participants mentioned not only kinds of self-care and housework but also forms of out-of-home mobility for instance, walking, going into town and going out and about - to illustrate their self-reliance and ability to do things:

"I appreciate the fact that I can get out and about and I can do things for myself, it helps me to remain independent. And I can go out and do my shopping, get my paper, travel. If I travel I, you know, I could do it if I need."

Paula, 86 years, single, urban area in Greater London

Moreover, the intricacies of getting and asking for rides from relatives and friends were often discussed in relation to not depending on others. Johanna, who lived in a low-density area in Oxfordshire and had given up driving on doctor's advice, explained that she preferred getting a lift to a shop over having groceries delivered to her house. However, she didn't want to ask for rides too often and was very careful about whom to ask for lifts to avoid the formation of more structural and durable relationships of dependence:

"There are a few people who will offer it [rides], but not many who I would ask because I think to them, and I know the feeling, that once they do it, they have to do it again, you know. So I try not to ask too many people." 
Johanna, 82 years, never married, low-density area in Oxfordshire

\section{2| Preference for independent mobility}

A further way in which independence and mobility were linked was that many participants actively sought to secure what they understood as independent mobility. On their view, this is mobility in which significant others - relatives, friends, neighbours - play a limited role (if any) and over which they can exercise decisional autonomy in terms of when and where to go. Overall, four strategies through which participants secured independent mobility as an alternative or complement to rides provided by others could be identified. These included, perhaps unsurprisingly, driving a car oneself as long as possible or permissible; walking with devices; using buses; and using taxis. The last two were discussed less frequently and more cautiously than the first two. The extent to which buses were perceived as affording independent mobility depended very much on people's residential location and its accessibility by buses. This pertained not only to distance to the nearest bus stop, but also to the time of the day and day of the week - many participants, including Robert below, considered buses only adequate during daytime on weekdays - and the number of transfers and walking time required to reach relevant destinations. Those respondents who discussed taxis also spoke about the monetary costs involved, which prompted them to ration the use of taxi services. The case of taxi use shows clearly that income and social conditions more generally are implicated in the production of independence alongside bodies, technologies, and infrastructures.

Like previous studies (Siren and Hakamies-Blomqvist, 2009; Ziegler and Schwanen, 2011), we see that older people - and older men in particular - use the car as a 'compensation tool' when their physical functioning declines. This is exemplified by 79 -year old Robert who resides in a highdensity location in Derbyshire and considers himself invalid: 
Interviewer: And you still drive don't you?

Robert: I still drive, yes.

Interviewer: And what does that mean to you being able to drive?

Robert: It means a lot because it means we're able to get out when we want, because at weekends when the bus service is finished, like on Sundays, you can't get out because there's no buses. Only once about every 12 hours probably! But no, if you want to get out on a Sunday either somebody picks you up or you need a car to get out yourself. Of course buses stop at 6 o'clock so you need a car if you want to get out in an emergency or anything like that, or go out to the theatre.

Interviewer: And what else do you use the car for?

Robert: Well mainly around the countryside and go shopping actually, you need it to go shopping because the weight of the shopping bags these days. I mean like [name of a supermarket chain]'s car park down there, just park there, park in the disabled and get a trolley and it's just easier for shopping really. Because if you're getting on and off the buses, you just can't do it with the shopping. So it helps. You do need a car. Anybody who hasn't got a car you can, you know you're cut off because you've got to rely on somebody else like all these single people. They're just sat in the house all day and that's why I offer to take them out now and again.

Interviewer: So it's quite important for independence as well then do you think?

Robert: Oh yes, yes definitely.

For Robert the car affords independence in the sense of both self-reliance and decisional autonomy that buses cannot replicate. By aligning himself to the technology of the car, he - or rather the assemblage of human body and car or driver-car (Dant, 2004) - can go places he cannot reach on foot or by bus when he wishes or needs to visit them; the 'ageing driver-car' is imbued with a motility, spontaneity, autonomy and sense of control that (he feels) cannot be replicated with other transport modes. Interestingly, Robert also expresses a certain level of awareness of the unfreedoms for, and subordination of, non-car users that the system of 
automobility causes (Sheller, 2008; Freudendal-Pedersen, 2009; see also Urry, 2007), and he therefore uses his driver-car capacities to occasionally extend the motility of older adults who cannot drive.

\subsection{Achievement and adjustment}

In light of the above it is unsurprising that older adults, such as Robert, are reluctant to give up driving, which for them constitutes a loss, a symbol of becoming old. Driving a car, however, is an embodied practice and different cars offer different competences or affordances (Gibson, 1979) to driver-car assemblages. Hence, the changes in a person's physical competences associated with bodily ageing can trigger a process of mutual adjustment, one in which cars are adjusted to the ageing body and vice versa - new bodily competences and motor skills are produced (Winance, 2007). This is the case for Peter (see Section 4) who suffers from arthritis:

Interviewer: And what about driving, how important is it for you to be able to keep driving? Peter: Oh, very important for me! I've always been one of these chaps that, you know, I might say oh I'll get up in the morning and off I'll go somewhere, you know, so in that aspect I need a car. I haven't even got a bus pass but no it is, I've got this, I've got an auto and I've never had power steering. Also my seat I can raise up to get out of the car easier as well so I do enjoy a lot more than I used to. So it's a rather nice car for my needs! (laughs)

Peter associates driving with the ability to do things, decisional autonomy and spontaneity. His words also suggest that the ability to drive comfortably is not given but something that emerges out of a process of adjustment in which power steering and a movable chair mediate the stiffness and reduced mobility in his joints. Independence is indeed an achievement that requires work and is produced from shifting relations between a changing human body and technological artefacts. 
That independent mobility is an achievement is also evident from the narratives of participants with walking difficulties who nonetheless favour walking over getting rides for trips over short distances. Anne (see Section 4) bought what she called a "two-wheeler", a tripod with small wheels and two bike handlebars to hold as she didn't want to burden her daughter:

"I don't like keep asking "can I go there?" while I can manage it, and that's why I bought my twowheeler. [...] my eldest granddaughter had bought me a stick. I was getting a bit uncertain. After I'd had my illnesses, I lost my balance a bit and I lost my confidence too and it took a while to get it back and I don't need a stick in the house but when I'm going out. Last summer my neighbour [...] took me out for walks round the block. We tried to go a different way each day. Oh well! I was exhausted! There wasn't enough support with a stick. I was clutching it like grim death and putting my weight on it and I was all tense down this side when I came back and [...] felt I'd run a marathon! And I thought to myself: "No, it [the stick]'s alright if I go to a garden centre or go round a car boot sale ... Stopping and starting, a stick is alright just for that, but not to go from A to B". I said to my daughter: "It's no good, I've got to have more support".

When I first had my wheelie, we had those lovely days early on when it was sunny and warm [...] and I used to get up and have my breakfast: "Right, I'm going out for a walk". I just used to leave everything and take my wheelie and I ventured round here. I desperately wanted to go down [name of road] and go into the recreation ground, because that had been our stamping ground when we were young and I hadn't been in the actual rec for ages. And the day I did that, I came back and I'd done it! I felt marvellous! And I was doing that and going round streets that had sort of been grown up since I moved up here and looking at people's gardens and, yeah, I quite enjoyed it, I said to my daughter and she said: "have you been gallivanting again?". I said: "yeah, if you can call it gallivanting", but it was lovely. Just to get out in the air, independent of everybody, I really enjoyed it. I came back and I don't say I, I won't say I fell to work with such gusto, but I felt up to doing something, I felt taken out of myself!"" 
Anne's narrative shows clearly that independent mobility results from a trial-and-error process of adjustment. It is within this process that Anne learns that different body-and-device assemblages offer different action possibilities and create different lived bodies: a stick is not required within her home, good enough for strolling in a market but inadequate for a trip from an origin to a destination. Another device is needed for the latter. Bodily competences, then, emerge only in specific contexts and differences across contexts can be substantial, as indicated by the contrast between exhaustion ("I felt I'd run a marathon") and presence-to-hand (Heidegger, 1962; Schillmeier, 2008) on the one hand and fitness ("I felt up to doing something") and readiness-tohand on the other. Further, if the body-cum-device assemblage creates a context that is Zubanden rather than Vorbanden, trips to not-too-distant destinations boost Anne's confidence, control and decisional autonomy and are a source of joy and a sense of achievement. Walking makes her proud and, in a way, young by reconfiguring what her body can do:

It keeps me upright, because I've always tried to keep upright, many of these old dears, they've got them, but they were walking over them like that instead of walking up, and I said: "I want to keep upright", and my daughter said: "mum, you're walking as if you've had this for ages".

Anne's process of adjustment involved not only her body/mind and devices; other persons - in particular her neighbour and daughter - also played significant parts as well, as did a wide range of non-human actants, including the weather, the recreation grounds and Anne's own memories which triggered her trip to those grounds (not to mention the roads, gardens, and so on). She made the trip when the weather was favourable; the importance of the weather became evident when she explained at another moment during the interview that she had used a taxi to get around in the days prior to the interview because the weather had been too warm. 


\subsection{Independence as event}

Whilst independence in mobility results from processes of adjustment, the participants' narratives also indicate that this independence is an unstable product of the relations between bodies, technologies, infrastructures and other human beings. It can become undone and is better thought of as a particular event amidst "a complex of passing events" (Whitehead, 1920, page 166). As we saw in Peter's case above, independent mobility is strongly dependent on the distribution of competencies between the specific car he drives and his own (and changing) body competencies. Anne's case, in which the weather was of non-trivial importance, also suggests that in/dependence is performed in a particular set of relations. And Robert's independence is to some extent dependent on specific relations: if the disabled car park is full when he goes shopping, his ability to do things is different from when he can use it to park his car.

Other interviews also suggested that in everyday mobility participants continually move in and out of moments of more or less in/dependence - here understood as in/ability to do things not unlike the visually impaired participants in Schillmeier's (2008) study. Thus, for Paul, a 80year old divorcee from Merseyside, getting into and out of his own car is fine but doing so in someone else's car is "awkward", a situation of presence-to-hand. For Robert, while buses in general afforded independence (in the sense of ability to do things without the help of others), this crucially depended on (most) local buses having lower steps and seats at the front of the bus being reserved for disabled people. Finally, Mary (see Section 4) explained how she prefers to use a stick rather than a wheelchair when she goes grocery shopping. Whilst acknowledging that it might help her in other circumstances, she "wouldn't go shopping in one [a wheelchair]" because she "can't get near the things"; it does not allow her to examine what she buys. Thus, independent mobility in later life is a precarious process in which an older person's capacities to move through space, their motility, continually expand and contract. Those capacities can be 
reduced through events and processes at multiple temporal scales. The latter include bodily ageing as well as encounters with other people and artefacts - specific vehicles, bus drivers, street crossings, building entrances, a lack of parking places in particular space-times, and so on.

\section{6| Final thoughts}

We have shown that participants' situated understandings of independence in later life are complex, fuzzy, shifting and include one another but also that they tend to think of trips outside the home in dualistic terms as either dependent - as relying on other human agents for lifts - or as independent - when they can drive, walk or use buses and taxis. Most participants also preferred to substitute independent for dependent mobility, which aligns with their more general desire to avoid burdening next of kin, friends and others. Whilst this may make intuitive sense, we feel there are two issues or concerns here. Firstly, from an ANT-inflected perspective, dualistically opposing independence and dependence and independent and dependent mobility is problematic: both independence and mobility are fabricated out of myriad relations with and dependencies on bodies, technologies, infrastructures, social networks and other forms of materiality (as well as social conditions). Analytically it would be more accurate to say that older adults avoiding lifts are trading dependencies on one kind of human-machine assemblage for assemblages that produce a more intensely technology-dependent form of independence.

Secondly, the study participants' equation of independent mobility with not relying on lifts by others inadvertently and paradoxically reproduces ageist yet widespread understandings of about dependency in old age as undesirable and indecent, and inadvertently subordinates older people who are primarily dependent on lifts or care-giving by next of kin, friends or others more generally. 
At the same time, we appreciate the good reasons why older adults like Robert, Peter and Anne favour an independence mediated by such technologies as buses, cars and walking sticks over lifts. For one, substituting artefacts for human assistance allows older people to circumvent the need to balance or repay the efforts of relatives, friends or neighbours: Cars, buses and sticks are not tied to older adults through internalised norms of reciprocity and balancing of care, which were important themes in how participants talked about relatives, friends, neighbours and others during the interviews. The significance of those themes among study participants resonates with recent studies in New Zealand (Stephens and Breheny, 2009) and the UK (Weicht, 2010) emphasising how older adults often avoid dependence on others for fear of not being able to reciprocate and of becoming entangled in unequal power relations.

Further, drawing on such technologies as cars and walking sticks rather than lifts allows older adults to assemble a 'normal' subject position and identity for themselves more easily (see also Moser, 2006). This identity reflects the socially produced ideal of the ageing subject who is active and socially connected without burdening relatives, neighbours and others, as well as in charge of his/her body and the devices used. Crucial here is that technical artefacts allow a socially mediated lived body (Butler and Bowlby, 1997) to emerge whose entanglement in webs of sociomaterial relations moves to the background more easily (Moser, 2006). Compared to humans, the agentive capacities of technical artefacts are more limited and their performance more standardised (Brown and Middleton, 2005; Schwanen, 2007), which facilitates emotional adjustment processes (Winance, 2007). As a result, artefacts are integrated into ageing lived bodies more easily; movement through geographical space becomes more fluid; and older adults are made less aware of their bodies when using walking sticks or adjusted cars than when relying primarily on other humans for getting around. In short, older adults' lived bodies recede in the background more quickly and more frequently, even though - as Schillmeier's (2008) and our 
own analyses have indicated - they pass continually through situations of more and less readiness-to-hand and independence whilst moving through physical space.

How then should independence in mobility, in later life, and more generally be understood from a geographical perspective? We offer a multi-layered reply. On one level, it is an unstable relational outcome fabricated out of dependencies on bodies, artefacts, social networks, other forms of materiality and such resources as financial means. Our use of 'dependencies' rather than relations or attachments here is purposive and a form of ontological politics (Mol, 1999). Like Weicht (2010, page 218), we “embrace dependency” to affirm that individuals' enmeshment in relations with both fellow humans and non-human elements is primordial to independence and indispensible to the human condition rather than preliminary or occasional. It is to highlight that dependencies are a normal aspect of human being; to contest the ideological connotations of dependence with passivity, burden and undesirability; and to resist the privileging of independence over dependence. As such, the affirmation of dependencies offers a basis for resisting ageist forms of identity and subjectivity formation whereby dependency in later life is made into an "other" against which actively and successfully ageing subjects compare favourably.

But there is more to independence than instability and fabrication: On a second level independence is about enablement and autonomy. Ability to do things was after all the second most widespread meaning associated with independence in Section 4 and out-of-home mobility, including trips from $\mathrm{A}$ to $\mathrm{B}$, was one of the practices participants mentioned to illustrate that ability. Moreover, a relational conception of autonomy can be said to refer to the character and quality of the dependencies on bodies - both one's own and those of one's partner, relatives, neighbours and other helpers -, technologies, infrastructures and so on, in which individuals are enmeshed ( $c f$. Moser and Law, 1999; Kullman, 2010). It is produced when (older) people are able to work with and improvise given those dependencies, can shape them to some extent, and can 
shift between different arrangements of them relatively easily. Combining this understanding of autonomy with the importance of enablement, we propose that at least in countries like the UK independence in later life revolves centrally around being capable of engaging everyday activities and the sites where these unfold - the home, public spaces, transport vehicles and shops, for instance, but increasingly also websites, computer programmes and mobile phone applications relatively fluidly. This requires that individuals are able to work with the bodies, technologies, infrastructures, etc. they encounter and can integrate these into their lived bodies with limited effort. This also entails that mobilities in which a partner, relatives, neighbours and other are actively involved can still be considered independent.

There is also a third layer to independence. Whilst our empirical analysis centred on individuallevel understandings and practices of independence, Robert (Section 5.2) alluded to the unfreedom the car-mediated independence of some can create for others. This is also what Sheller (2008) and Freudendal-Pedersen (2009) highlighted (see Section 2.3). Independence also has group-level dimensions and intersects with questions of social equality. Questions can be raised about the desirability of forms of independence for some older adults that are produced at the expense of others' ability to do things. This, for us, is where Peter's and Robert's practiced independence, which is firmly ensconced in the system of automobility (Urry, 2007) and its inequalities, differs from Anne's. Hers is more egalitarian and benign in a social sense. The motility that car driving offers to older adults is often crucial to their independence and wellbeing (Siren and Hakamies-Blomqvist, 2009; Ziegler and Schwanen, 2011) and the car's role is likely to increase for future cohorts of older adults ageing in place. But a key challenge for social, land use and transport policy will be to avoid growing inequalities in opportunities to become and remain independent among elders who can drive and those who cannot drive for medical, financial and other reasons. 
Our reply suggests, then, that independence in later life both in connection to mobility and more generally is indeed a multiplicity. Whilst we refer to three levels above, we also think these melt into each other and constitute an organic whole in everyday life; the real challenge is to think independence as a Bergsonian qualitative multiplicity. Moreover, although this paper has considered older people,we are inclined to believe this understanding of independence extends to the everyday practices (which include mobility) at other life-course stages and to other social groups. This assertion, however, needs to be verified in future research.

On the basis of the empirical study we did conduct we argue that independent mobility in later life is more than not being dependent on lifts by others, just as independent mobility for children is more than travelling alone or not being chauffeured by parents (Mikkelson and Christensen, 2009; Kullman, 2010). Understandings and discussions of independent mobility in later life should include the following elements: older adults' ability to move fluidly through geographical space; their ability to do things at different sites in geographical space and thereby be socially connected, participate in civil society, and enact desired identities; the relational autonomy enabling them to switch between different bundles of relations with technologies and fellow humans for integration into their ageing and moving lived bodies; and forms of freedom and motility that do not empower some older adults at the expense of others.

\section{References}

Adey, P., 2010. Mobility. Routledge, Abingdon.

Adler, G., Rottunda, S., 2006. Older adults' perspectives on driving cessation. Journal of Aging Studies 20(3), 227-235.

Anderson, B., McFarlane, C., 2011. Assemblage and geography. Area 43(2), 124-127.

Andrews, G.J., Cutchin, M., McCracken, K., Phillips, D.R., Wiles, J., 2007. Geographical gerontology: the constitution of a discipline. Social Science \& Medicine 65(1), 151-168. 
Audit Commission, 2004. Older People - Independence and Well-Being: The Challenge for Public Services. Audit Commission, London. Available at http://www.auditcommission.gov.uk/SiteCollectionDocuments/AuditCommissionReports/NationalStudies/Olde rPeople overarch.pdf.

Ball, M.M., Perkins, M.M., Whittington, F.J., Hollingsworth, C., King, S.V., Combs, B.L., 2004. Independence in assisted living. Journal of Aging Studies 18(4), 467-483.

Bauer, M.J., Rottunda, S., Adler, G., 2003. Older women and driving cessation. Qualitative Social Work 2(3), 309-325.

Bauman, Z., 2000. Liquid Modernity. Polity, Cambridge.

Beck, U., Giddens, A., Lash, S., 1994. Reflexive Modernization: Politics, Traditions and Aesthetics in the Modern Social Order. Stanford University Press, Stanford, CA.

Bergson, H., 1913. Time and Free Will: An Essay on the Immediate Data of Consciousness. George Allen and Co., Ltd., London.

Brisenden, S., 1986. Independent living and the medical model of disability. Disability, Handicap \& Society 1(2), 173-178.

Breheny, M., Stephens, C., 2009. 'I sort of pay back in my own little way': managing independence and social connectedness through reciprocity. Ageing and Society 29(8), 12951313.

Brown, S.D., Middleton, D., 2005. The baby as virtual object: agency and difference in a neonatal intensive care unit. Environment and Planning D: Society and Space 23(5), 695-715.

Butler, R., Bowlby, S., 1997. Bodies and spaces: an exploration of disabled people's experiences of public space. Environment and Planning D: Society and Space 15, 411-433.

Cardol, M., De Jong, B.A., Ward, C.D., 2002. On autonomy and participation in rehabilitation. Disability and Rehabilitation 24(18), 970-974.

Callon, M., Law, J., 1995. Agency and the hybrid collectif. South Atlantic Quarterly 94(2), 481 507.

Clapton, J., Kendall, E., 2002. Autonomy and participation in rehabilitation: time for a new paradigm? Disability and Rehabilitation 24(18), 987-991.

Collopy, B.J., 1988. Autonomy in long term care: some crucial distinctions. The Gerontologist 28(Suppl.), 10-17.

Coughlin, J., 2001. Transportation and Older Persons: Perceptions and Preferences. AARP, Public Policy Institute, Washington, D.C.

Cresswell, P., 2011. Mobilities I: Catching up. Progress in Human Geography 35(4), 550-558.

Cutchin, M.P., 2003. The process of mediated aging-in-place: a theoretically and empirically based model. Social Science \& Medicine 57(6), 1077-1090. 
Dant, T., 2004. The driver-car. Theory, Culture \& Society 21(4-5), 61-79.

Davey, J., 2007. Older people and transport: coping without a car. Ageing and Society 27(1), 4965.

De Laet, M., Mol, A., 2000. The Zimbabwe bush pump: mechanisms of a fluid technology. Social Studies of Science 30(2), 225-263.

Depp, C.A., Jeste, D.V., 2006. Definitions and predictors of successful aging: a comprehensive review of larger quantitative studies. American Journal of Geriatric Psychiatry 14(1), 6-20.

Fine, M., Glendinning, C., 2005. Dependence, independence or inter-dependence? Revisiting the concepts of 'care' and 'dependence'. Ageing \& Society 25(4), 6001-621.

Freudendal-Pedersen, M., 2009. Mobility in Daily Life: Between Freedom and Unfreedom. Ashgate, Aldershot.

Gabriel, Z., Bowling, A., 2004. Quality of life from the perspectives of older people. Ageing and Society 24(5), 675-691.

Gibson, J.J. 1979. The Ecological Approach to Visual Perception. Houghton Mifflin, Boston, MA.

Haak, M., Fänge, A., Iwarsson, S., Ivanoff, S.D., 2007. Home as a signification of independence and autonomy: experiences among very old Swedish people. Scandinavian Journal of Occupational Therapy 14(1), 16-24.

Heidegger, M., 1962. Being and Time. Harper \& Row, New York.

Hillman, M., Adams, J., Whitelegg, J., 1990. One False Move. Policy Studies Institute, London.

Hinchliffe, S., 2010. Working with multiples: a non-representational approach to environmental issues. In: Anderson, B., Harrison, P. (Eds.), Taking-Place: Non-Representational Theories and Geography, pp. 303-320. Ashgate, Farnham.

Hunt, M.R., Ells, C., 2011. Partners towards autonomy: risky choices and relational autonomy in rehabilitation care. Disability and Rehabilitation 33(11), 961-967.

Kant, I. (1997[1785]) Groundwork of the Metaphysics of Morals, translated by M. Gregor. Cambridge University Press, Cambridge.

Kaufman, S., 1986. The Ageless Self: Sources of Meaning in Late Life. Meridian, New York.

Kaufman, V., 2002. Re-thinking Mobility. Ashgate, Aldershot.

Kesselring, S., 2006. Pioneering mobilities: new patterns of movement and motility in a mobile world. Environment and Planning A 38(2), 269-279.

Kullman, K., 2010. Transitional geographies: making mobile children. Social \& Cultural Geography 11(8), 829-846 
Laliberte Rudman, D., 2006. Shaping the active, autonomous and responsible modern retiree: an analysis of discursive technologies and their links with neo-liberal political rationality. Ageing and Society 26(2), 181-201.

Latour, B., 1987. Science in Action: How to Follow Scientists and Engineers through Society. Harvard University Press, Cambridge, MA.

Law, J., 2004. After Method: Mess in Social Science Research. Blackwell, London.

Law, J., 1986. On the methods of long-distance control: Vessels, navigation and the Portuguese route to India. In: Law, J. (ed.) Power, Action and Belief: A New Sociology of Knowledge?, pp. 234-263. Routledge, London.

Leece, J., Peace, S., 2010. Developing new understandings of independence and autonomy in the personalized relationship. British Journal of Social Work 40(6), 1847-1865.

López, D., Domènech, M., 2009. Embodying autonomy in a home telecare service. Sociological Review 56(s2), 181-195.

Lucas, S., Burnett, P., 2010. Talking, walking, riding and driving: the mobilities of older adults. Journal of Transport Geography 18(5), 596-602.

Mack R., Salmoni, A., Viverais-Dressler, G., Porter, E., Garg, R. 1997. Perceived risks to independent living: the views of older, community-dwelling adults. The Gerontologist 37(6), 729736.

McFarquhar, T., Bowling, A., 2008. Older People's Understanding of 'Active Ageing' and its Influence on Quality of Life: A Qualitative Study. Department of Primary Care and Population Health, University College London.

Merleau-Ponty, M., 1962. Phenomenology of Perception. Routledge, London.

Mill, J.S., 1859. On Liberty. Available at: http://www.utilitarianism.com/ol/one.html (Last Accessed 2 April 2012).

Mikkelsen, M.R., Christensen, P., 2009. Is children's independent mobility really independent? A study of children's mobility combining ethnography and GPS/mobile phone technologies. Mobilities 4(1), 37-58.

Mol, A., 2002. The Body Multiple: Ontology in Medical Practice. Duke University Press, Durham, NC.

Mol, A., 1999. Ontological politics: a word and some questions. In: Law, J., Hassard, J. (Eds.) Actor Network Theory and After, pp. 74-89. Blackwell, Oxford.

Moser, I., 2006. Disability and the promises of technology: technology, subjectivity and embodiment within an order of the normal. Information, Communication \& Society 9(3), 373395. 
Moser, I., Law, J., 1999. Good passages, bad passages. In: Law, J., Hassard, J. (Eds.) Actor Network Theory and After, pp. 196-219. Blackwell, Oxford.

Mowl, G., Pain, R., Talbot, C., 2000. The ageing body and the homespace. Area 32(2), 189-197.

Peace, S., Holland, C., Kellaher, L., 2011. 'Option recognition' in later life: variations in ageing in place. Ageing and Society 31(5), 734-757.

Plath, D., 2008. Independence in old age: the route to social exclusion? British Journal of Social Work 38(7), 1353-1369.

Portacolone, E., 2011. The myth of independence for older Americans living alone in the Bay Area of San Francisco: a critical reflection. Ageing and Society 31(5), 803-828.

Reckwitz, A. 2002. Toward a theory of social practices: a development in culturalist theorizing. European Journal of Social Theory 5(2), 243-263.

Reindal, S.M., 1999. Independence, dependence, interdependence: some reflections on the subject and personal autonomy. Disability \& Society 14(3), 353-367.

Risser, R., Haindl, G., Ståhl, A., 2008. Barriers to senior citizens' outdoor mobility in Europe. European Journal of Ageing 7(2), 69-80.

Rock, P.J., 1988. Independence: what it means to six disabled people living in the community. Disability, Handicap \& Society 3(1), 27-35.

Rowe, J.K., Kahn, R.L., 1987. Human aging: usual and successful. Science 237(4811), 143-149.

Rowles, G., 1993. Evolving images of place in aging and "aging in place". Generations 17(1), 6570 .

Sager, T., 2006. Freedom as mobility: implications of the distinction between actual and potential travelling. Mobilities 1(3), 465-488.

Schillmeier, M., 2008. Time-spaces of in/dependence and dis/abilty. Time \& Society 17(2/3), 215-231.

Schmöcker, J.D., Quddus, M.A., Noland, R.B., Bell, M.G.H., 2008. Mode choice of older and disabled people: a case study of shopping trips in London. Journal of Transport Geography 16(4), 257-267.

Schwanen, T., 2007. Matter(s) of interest: artefacts, spacing, timing. Geografiska Annaler, Series B: Human Geography 89(1), 9-22.

Secker, J., Hill, R., Villeneau, L., Parkman, S., 2003. Promoting independence: but promoting what and how? Ageing \& Society 23(3), 375-391.

Sen, A., 1999. Commodities and capabilities. Oxford University Press, Oxford. 
Sheller, M., 2008. Mobility, freedom ad public space. In: Bergman, S., Sager, T. (Eds.), The Ethics of Mobilities: Rethinking Place, Exclusion, Freedom and Environment, pp. 25-38. Ashgate, Aldershot.

Siren, A., Hakamies-Blomqvist, L., 2009. Mobility and wellbeing in old age. Topics in Geriatric Rehabilitation 25 (1), 3-11.

Smith, J.A., Braunack-Mayer, A., Wittert, G., Warin, M. 2007. "I've been independent for so damn long!": independence, masculinity and aging in a help seeking context. Journal of Aging Studies 21(4), 325-335.

Stephenson, P., Wolfe, N., Coughlan, R., Koehn, S.D., 1999. A methodological discourse on gender, independence and frailty: applied dimensions of identity construction in old age. Journal of Aging Studies 13(4), 391-401.

Struhkamp, R.M., 2005. Patient autonomy: a view from the kitchen. Medicine, Health Care and Philosophy 8(2), 105-114.

Struhkamp, R., Mol, A., Swierstra, T., 2009. Dealing with in/dependence. Science, Technology \& Human Values 34(1), 55-76.

Townsend, P., 1981. The structured dependency of the elderly: a creation of social policy in the twentieth century. Ageing and Society 1(1), 5-28.

United Nations, 2002. Report of the Second World Assembly on Ageing. Madrid, 8-12 April 2002. United Nations, New York. Available at: http://daccess-dds-

ny.un.org/doc/UNDOC/GEN/N02/397/51/PDF/N0239751.pdf?OpenElement.

Urry, J., 2007. Mobilities. Polity, Cambridge.

Weicht, B., 2010. Embarcing dependency: rethinking (in)dependence in the discourse of care. The Sociological Review 58(s2), 205-224.

Winance, M., 2007. Trying out the wheelchair: the mutual shaping of people and devices through adjustment. Science, Technology and Human Values 31(1), 52-72.

Whitehead, A.N., 1920. The Concept of Nature. Cambridge University Press, Cambridge.

World Health Organization, 2002. Active Ageing: A Policy Framework. Available at: http://whqlibdoc.who.int/hq/2002/WHO NMH NPH 02.8.pdf.

Ziegler, F., Schwanen, T., 2011. "I like to get out to be energized by different people": An exploratory analysis of mobility and wellbeing in later life. Ageing and Society 31(5), 758-781. 